\section{PRÁTICAS PEDAGÓGICAS PARA \\ A LEI No 10.639/2003: A CRIAÇÃO \\ DE NOVA ABORDAGEM DE \\ FORMAÇÁO NA PERSPECTIVA \\ DAS AFRICANIDADES}

Sandra Haydée Petit ${ }^{l}$

Práticas Pedagógicas para a Lei № 10.639/2003: A Criação de Nova Abordagem de Formação na Perspectiva das Africanidades

\title{
Resumo
}

A partir de nossa experiência de formação de professores para atuação em quilombos, passamos a criar uma nova abordagem de ensino e pesquisa de intervenção na perspectiva das africanidades e que denominamos de Pretagogia. O presente artigo apresenta inicialmente uma breve discussão fundamentando a necessidade de abordagem de ensino e pesquisa condizente com os propósitos da Lei no 10.639/2003 e que busque seu embasamento teórico-metodológico nas africanidades recriadas no Brasil e no continente americano em geral. Em seguida, focamos os resultados de algumas estratégias de ensino e procedimentos de pesquisa de intervenção que vêm contribuindo para a formação de professoras(es) nos Institutos de Ensino Superior na perspectiva da referida lei.

Palavras-chave: Pesquisa de intervenção.

Africanidades. Formação de professoras(es). Lei no 10.639/2003. Práticas pedagógicas.

1 Professora da Universidade Federal do Ceará. Doutora e mestra em Ciências da Educação pela Université Paris 8 - Vincennes-Saint-Denis, PARIS 8, França. Graduada em Línguas Estrangeiras Aplicadas pela Université Paris 8 - Vincennes-Saint-Denis, PARIS 8, França. Coordenadora do Núcleo das Africanidades Cearenses (NACE). 
EDUCATIONAL PRACTICES FOR LAW 10,639/2003: THE CREATION OF A NEW QUALIFICATION APPROACH ON THE PERSPECTIVE OF THE AFRICANITIES

\begin{abstract}
From our teacher training experience to work in kilombos, we created a new approach to teaching and research-intervention from the perspective of africanities, something we called black-pedagogy. This article first presents a brief discussion basing the need for a teaching and research approach compatible with the purposes of the Law 10,639/2003, and that pursues its theoretical and methodological basis in africanities recreated in Brazil and in the American continent in general. Subsequently, we focus on the results of some teaching strategies and researchintervention procedures that are contributing to the training of teachers in the Graduation Institutes under the perspective of the mentioned law.
\end{abstract}

Keywords: Research-intervention. Africanities. Teacher training. Law 10,639/2003. Pedagogical practices. 


\section{PRÁTICAS PEDAGÓGICAS PARA A LEI No 10.639/2003: A CRIAÇÃO DE NOVA ABORDAGEM DE FORMAÇÃO NA PERSPECTIVA DAS AFRICANIDADES}

\section{PALAVRAS INTRODUTÓRIAS}

Tratamos, no presente trabalho, a construção em curso da Pretagogia, enquanto referencial teórico-metodológico que pretende potencializar as influências africanas, afro-brasileiras e afrodiaspóricas na nossa educação, transformando-as em contribuições didático-pedagógicas e curriculares. Antes de abordar a Pretagogia, trazemos à memória as conquistas que contextualizam o surgimento e importância da Lei $n^{\circ}$ 10.639/03, que institui a obrigatoriedade do ensino da história e cultura africana e afro-brasileira nas escolas, e que motivou os NEABs (Núcleos de Estudos Afro-Brasileiros) a produzirem subsídios para a sua implementação. Em seguida, fornecemos exemplos e breve discussão sobre formas de pesquisa de intervenção que a Pretagogia propicia e o que pode resultar em termos de práticas de produção didática facilitadoras de apropriaçáo do pertencimento afro.

\section{BREVE CONTEXTUALIZAÇÁO}

Em 9 de janeiro de 2003, a Lei $n^{\circ} 10.639$ alterou a Lei de Diretrizes e Bases (LDB no 9.394/96) nos seus artigos 26 e 79, tornando obrigatória a inclusão no currículo oficial de ensino as temáticas "História e Cultura Afro-brasileira". O texto da lei é incisivo e claro quanto aos objetivos da mudança. Os parágrafos explicitam:

$\$ 1^{\circ}-\mathrm{O}$ conteúdo programático a que se refere o caput deste artigo incluirá o estudo da História da África e dos Africanos, a luta dos negros no Brasil, a cultura negra brasileira e
Práticas Pedagógicas para a Lei № 10.639/2003: A Criação de Nova Abordagem de Formação na Perspectiva das Africanidades 
o negro na formação da sociedade nacional, resgatando a contribuição do povo negro nas áreas social, econômica e política pertinentes à História do Brasil;

$\$ 2^{\circ}$ - Os conteúdos referentes à História e Cultura Afro-brasileira serão ministrados no âmbito de todo o currículo escolar, em especial nas áreas de Educação Artística e de Literatura e História Brasileiras.

A lei também estabelece que o calendário escolar incluirá o dia 20 de novembro como "Dia Nacional da Consciência Negra". Também se constitui como marco nas leis educacionais a aprovação unânime em 10/3/2004, pelo Conselho Nacional da Educação, das "Diretrizes Curriculares Nacionais para a Educação das Relaçôes Étnico Raciais”, sob coordenação da professora Petronilha Beatriz Gonçalves da Silva (2004). A Lei no $10.639 / 2003$ será seguida em 2008 pela Lei no 11.645 , a qual acrescenta a obrigatoriedade do ensino da história e cultura indígena nas escolas.

Podemos dizer que ambas as leis fazem parte das políticas educacionais de integração, atendendo às reivindicaçôes originadas nas lutas dos diversos movimentos sociais étnicos. No caso da afrodescendência, são resultados da mobilização dos movimentos negros (desde o período escravagista, com as diversas insurreiçôes): a luta abolicionista, os movimentos quilombolas, as múltiplas formas de resistência cultural dos afrodescendentes, a atuação dos diversos grupos de feministas negras. Todos esses movimentos ganharam maior notoriedade pública a partir da década de 1980, com a articulação com outros movimentos sociais que foram levados a transversalizar a questáo negra a partir da insistente luta dos movimentos e de seus mediadores (RIBEIRO, 2014). Desde então, se constituiu uma área de educação afroreferenciada, notadamente a partir do final do século XX. 
Foram muitas as experiências pedagógicas preocupadas com o combate ao racismo e a promoçáo de outro conteúdo e metodologias, tais como os movimentos de Educação Popular Afrobrasileira, o projeto Irê Ayó (MACHADO, 2013) e a educação pluricultural africano-brasileira Oba Biyi (SANTOS; LUZ, 2007). Podemos acrescentar a isso o grande avanço nos subsídios criados, com a revisão dos livros didáticos, a formação e material do programa A Cor da Cultura e a multiplicação de livros infantojuvenis que retratam personagens negros e o mundo das africanidades de modo positivado, como as obras de Kiusam Oliveira, Heloisa Pires Lima, Joel Rufino, Rogério Andrade e Edimilson Pereira.

A questão étnico-racial ultrapassa o âmbito estrito do rechaço ao racismo e à discriminaçáo racial, a partir do marco histórico da Constituiçáo Federal de 1988, que torna relevante a intervenção na educação. Nesse contexto, o artigo 210 reconheceu o direito à educação indígena diferenciada, bem como o princípio da autonomia. Tal ação permitiu o reconhecimento das escolas indígenas diferenciadas criadas nas aldeias, o Magistério Indígena Diferenciado em nível médio e logo também em nível superior. Os índios conseguiram seu próprio Referencial Curricular Nacional da Educação Indígena, afinal não bastava assegurar o direito à terra: era necessário garantir o direito à educação e à cultura.

No campo dos avanços voltados para a populaçáo negra, a Lei $n^{\circ} 10.639 / 03$ foi um marco histórico de suma importância como política de reparação, valorização e afirmação, promovendo transformaçôes muito significativas no âmbito educacional em treze anos de sua promulgação.

Nessa política de integração, são seguidos os direitos dos quilombolas, que têm sua ênfase educacional nas Diretrizes Nacionais para a Educação Quilombola, Resolução no 8, de 20 de novembro de 2012, bem como, no âmbito das universidades, a Lei das Cotas $n^{\circ} 12.711 / 12$, bastante atacada pelos setores mais conservadores e reacionários da Educação por favorecer um aumento significativo da proporçáa de
Práticas Pedagógicas para a Lei № 10.639/2003: A Criação de Nova Abordagem de Formação na Perspectiva das Africanidades
Educ. Foco, Juiz de Fora, 661 s.21, n.3, p. 657-684, 
Sandra Haydée Petit (a)

Educ. Foco, negras(os) nas universidades públicas, atingindo inclusive os cursos elitizados.

\section{O REFERENCIAL TEÓRICO-METODOLÓGICO PRETAGOGIA E SEUS PRINCÍPIOS}

Mesmo com esse quadro de avanços importantes, se pensarmos nas mentalidades preconceituosas forjadas em mais de 500 anos de racismo virulento, notamos que são muito recentes para a nação essas conquistas. Essa constatação tem levado a nos ocupar em grande parte com a formação de professoras(es), pelo papel central que essa categoria profissional ocupa no repasse de valores para a vida.

Assim, nossos(as) pesquisadores(as) têm atuado tanto no ensino básico com os docentes em serviço, como na formação inicial universitária. $\mathrm{O}$ nosso grupo de pesquisa e intervenção, o NACE, para além de preencher as lacunas das formaçóes escolares e universitárias, tem se destacado em trabalhar concepçôes diferenciadas afroreferenciadas inovadoras.

Consideramos o corpo todo fonte e produtor de conhecimento, e não apenas o cérebro, envolvendo os cinco sentidos (visão, paladar, audição, tato e olfato). Desse modo, os docentes em serviço que participam das atividades do NACE enquanto formandos, assim como os estudantes universitários, têm tido a oportunidade de experimentar, pelo próprio corpo, abordagens teóricas que se inspiram na filosofia africana.

O termo filosofia abrange aqui náo apenas o pensamento de acadêmicos especialistas, e sim também fontes e saberes perpassados de oralidade, o que significa lidar com diversas linguagens da literatura oral, notadamente os ensinamentos milenares que nos são repassados em mitos, contos, provérbios e simbologias adinkras (ideogramas tradicionais da cultura acã em Gana).

Aproveitamos muito esses diversos suportes de literatura oral ultrapassando a comum concepção eurocêntrica que a filosofia se constrói essencialmente a partir da escrita alfabética. 
Se na própria Europa a linguagem escrita só começou a ser divulgada com o advento da imprensa no século XV até ter preponderância no século $\mathrm{XX}$, como considerar a filosofia estritamente atrelada à escrita alfabética greco-romana? Seria uma forma de negar as mais variadas filosofias milenares existentes no planeta em diversas categorias e classes de gente, como as múltiplas tradiçôes africanas, asiáticas e ameríndias. Ora, essas filosofias são baseadas em complexos sistemas que não segmentam os conhecimentos, pois interligam sabedoria, espiritualidade e ciência, tais como o Ifá iorubano, o I-Ching chinês (ambos oráculos) e a Ayurveda indiana.

Como afirma Hampâté Bâ (1982):

A tradição oral é a grande escola da vida, e dela recupera e relaciona todos os aspectos. Pode parecer caótica àqueles que não lhe descortinam o segredo e desconcertar a mentalidade cartesiana acostumada a separar tudo em categorias bem definidas. Dentro da tradição oral, na verdade, o espiritual e o material náo estão dissociados. Ao passar do esotérico para o exotérico, a tradição oral consegue colocarse ao alcance dos homens, falarlhes de acordo com o entendimento humano, revelarse de acordo com as aptidôes humanas. Ela é ao mesmo tempo religião, conhecimento, ciência natural, iniciação à arte, história, divertimento e recreação, uma vez que todo pormenor sempre nos permite remontar à Unidade primordial (BÂ, 1982, p. 183).

Reforça Oliveira (2006, p. 117): "Na visão de mundo africana tudo está em tudo, isto é, tudo se complementa. [...] A integração possibilita a conjugação das diferenças. [...] $\mathrm{O}$ que há são possibilidades diferenciadas de arranjos sociais, culturais, etc.".

Oliveira (2006) dá como exemplo a forma como essa cosmovisão considera a doença e o meio ambiente: a doença está ligada à saúde, não somente do corpo, mas a desequilíbrios
Práticas Pedagógicas para a Lei № 10.639/2003: A Criação de Nova Abordagem de Formação na Perspectiva das Africanidades
Educ. Foco, Juiz de Fora,

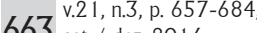


Sandra Haydée Petit

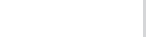

Educ. Foco, Juiz de Fora, v. 21, n.3, p. $657-684$ set. / dez. 2016664 sociais, políticos, econômicos e culturais. Está relacionado principalmente à dimensão espiritual, daí a importância de cuidar da espiritualidade, garantindo as devidas oferendas e agradecimentos para, em troca, receber saúde. $\mathrm{O}$ meio ambiente se interliga necessariamente à doença/saúde, pois este afeta não somente o corpo material, mas também a vida espiritual. Assim, a ecologia não é uma questão restrita ao ambiente natural:

O problema ecológico atinge todas as esferas da vida humana e de seu mundo [...]. Ou seja, a esfera da ecologia toca transversalmente todas as outras esferas, e como elas estão interligadas, seus efeitos se comunicam, seja positiva ou negativamente. É importante ressaltar que quando falamos em integração não é possível falar de uma espécie de elevação de um elemento como o mais importante. [...] Tudo é importante, na medida em que tudo está interligado com o todo (OLIVEIRA, 2006, p. 118).

A integração envolve necessariamente lidar com a diversidade: "A integração supóe uma abertura, uma flexibilidade, uma vez que seu modo operacional é dinâmico e não estático" (OLIVEIRA, 2006, p. 118). Podemos notar isso no modus operandi, tanto do africano como do afrodiaspórico: tratam-se de povos que funcionam pela adaptabilidade, flexibilidade e multiplicidade. A aceitação da diferença é intrínseca à cosmovisão africana porque ela é inclusiva.

É por isso que o outro é bem-vindo e bem tratado, o que gera um sentido de hospitalidade. Considera-se que sempre há espaço para todos, mais um, não é problema, pelo contrário, o outro é desejado: "[...] percebemos que para o africano o mais importante é estabelecer contato com o outro e que é nesta troca que se aprende a lidar com as diferenças que são a base para se exercer a complementaridade" (BERNAT, 2013, p. 31). Dessa forma, o diálogo com o outro instaura 
mais uma vez uma adaptabilidade, um convívio, uma troca. A homogeneidade não é o tom, e sim a convivência com o diferente:

Em um sistema integrado não éa homogeneidade que dá a tônica da organização social, mas a heterogeneidade. Percebe-se assim, que o distinto é contemplado; o diferente é desejado e náo apenas aceito. A diversidade é mãe da flexibilidade. É neste sentido que podemos dizer que a diversidade possui uma grande capacidade de adaptação e de re-significação, características facilmente identificadas nas religiốes de matriz africana (OLIVEIRA, 2006, p. 119).

Denominamos de pretagogia a abordagem teóricometodológica que parte de referências das filosofias que atravessam as tradições africanas e os estudos embasados em Bâ (1982), Munanga (2009), Sodré (1988; 2012), Cunha (2007), Oliveira (2006; 2007), Silva (2013), Cruz (2011), Meijer (2012), Videira (2010), dentre outros, para propor uma pedagogia que atualiza seus princípios nas culturas afrobrasileiras e afrodiaspóricas em geral a partir dos seguintes fundamentos: 1) o autorreconhecimento afrodescendente; 2) a tradição oral; 3) a apropriação dos valores das culturas de matriz africana; 4) a circularidade; 5) a religiosidade de matriz africana entrelaçada nos saberes e conhecimentos; 6) o reconhecimento da sacralidade; 7) o corpo como produtor espiritual, produtor de saberes; 8) a noção de território como espaço-tempo socialmente construído; 9) o reconhecimento e entendimento do lugar social atribuído ao negro.

A pretagogia prioriza a experiência de si e de outros(as) no mundo por meio do autorreconhecimento e dos valores das culturas africanas, articulando-os à transversalidade e à transposição didática. Como nas tradições africanas, o corpo é o principal vetor do conhecimento, incorporando natureza e mundo espiritual de forma integrada.
Práticas Pedagógicas para a Lei № 10.639/2003: A Criação de Nova Abordagem de Formação na Perspectiva das Africanidades
Educ. Foco, Juiz de Fora, $665^{\text {v.21, n.3, p. } 657-684}$ 
Sandra Haydée Petit

Educ. Foco, Juiz de Fora, v. 21, n.3, p. $657-684$ set. / dez. 2016666
Então percebemos que necessitávamos também de um modo de aproximação transversal das temáticas das africanidades (MUNANGA, 1984; SILVA, 2003). Para tanto, era primeiro indispensável identificar e afirmar a conexáo que nós, afrodiaspóricas(os), temos com o continente africano algo que o racismo secular institucionalizado ofusca, deprecia e mantém em um apagamento histórico.

Dessa forma, notamos que para professoras(es) a descoberta e a afirmaçáo de seu pertencimento afro se constituía um imenso desafio, por vezes uma barreira aparentemente instransponível, perpassado de medos e receios. Essa atitude se manifestava no distanciamento e na negação nas falas, com frequente uso da terceira pessoa do plural, ao se tratar de pessoas e elementos africanos ou afrodescendentes: "por que eles lá são...", "porque eles sofrem preconceito", "eles têm suas tradiçôes”. Como trazer para si as africanidades? Como gerar essa apropriação de si mesmo?

Consideramos que o caminho inicia na relaçáo autobiográfica com a africanidade, pelo que Luz (1998) chama de porteira de dentro. Abrir a porteira de dentro, em um conceito da tradição africana, significa conhecer sua história, situando-se em uma linhagem biológica e/ou simbólica/ espiritual e possui grande importância. Assim, o(a) sábio(a) africano(a), na figura do griot ou griote, ressalta sempre esse plano do existir, que une passado, presente e futuro.

Bâ (2003) ressalta que, segundo a tradição africana, toda pessoa só se apresenta ao mundo a partir da história de suas linhagens materna e paterna. Incorporar esse ensinamento nos leva a buscar conhecer de onde viemos, quem eram nossos antepassados e suas histórias. E mesmo para nós, afrodiaspóricos, nem sempre bem inteirados dessa história, se torna importante realizar a busca das histórias africanas que nos envolvem e marcam nosso pertencimento, seja ele biológico ou não, já que se trata fundamentalmente de relação de ancestralidade cultural, algo que todos nós possuímos. 
Diz Bernat (2013), a propósito do que aprendeu com o griot Sotigui Kouyaté, sobre a importância de partir de si ao criar uma obra de teatro:

Uma das coisas que mais impressionou os atores que participaram dos estágios com Sotigui foi o incentivo constante da parte dele para que cada um, antes de tudo, levasse em consideraçáo as suas raízes, tradiçōes, história familiar, ou seja, a compreensão de que não está fora de nós o início de qualquer jornada, de qualquer trabalho, não só como artistas, mas como homens e mulheres também (BERNAT, 2013, p. 192).

A partir da sistematização dos estudos e intervençóes do NACE, e fundamentalmente das minhas próprias experiências e análises, levantei 30 temáticas possíveis de identificação das africanidades nas nossas vidas, que não pretendem ser exaustivas das influências africanas na brasilidade, mas que reúnem, a meu ver, um escopo relevante de atravessamentos afro no nosso sistema cultural. Chamei tais elementos de marcadores das africanidades, isto é, marcas daquilo que nos conecta, desde membros da nossa linhagem, práticas religiosas e espirituais, artísticas, de saúde, culinárias, arquiteturas, presentes no cotidiano e na memória familiar e coletiva de todos os brasileiros, independentemente de sua cor de pele. Eis os marcadores, tais como descrevemos recentemente em artigo escrito em coautoria com Maria Kellynia Farias Alves (ALVES; PETIT, 2015):

1- História do meu nome

2- Histórias da minha linhagem, inclusive agregados

3- Mitos / lendas / o ato de contar / valorização da contação

4- Histórias do meu lugar de pertencimento / comunidade / territorialidades e desterritorialidades
Práticas Pedagógicas para a Lei № 10.639/2003: A Criação de Nova Abordagem de Formação na Perspectiva das Africanidades 
negras (movimentos de deslocamentos geográficos, corporais e simbólicos)

5- Sabores da minha infância - pratos, modos de comer e valor da comida

6- Pessoas referências da minha família e da minha comunidade e pessoas negras referências do mundo, significativas para mim

7- Simbologias da circularidade / tempos cíclicos e da natureza

8- Práticas e valores de iniciação / ritos de transmissão e ensino

9- Mestras(es) negras(os) - da cultura negra

10- Escrituras negras

11- Curas / práticas de saúde

12- Cheiros "negros" significativos

13- Festas da minha infância e festas de hoje

14- Lugares míticos e territórios afromarcados (investidos pela negritude)

15- Músicas / cantos / toques / ritmos / estilos afro

16- Danças afro

17- Cabelos afro (encaracolados / cacheados / crespo) práticas corporais de afirmação e negação dos traços negros diacríticos

18- Representaçóes da África / relaçóes com a África

19- Negritude - força e resistência

20- Artesanatos

21- Outras tecnologias

22- Valores de família / filosofias

23- Racismos (perpetrados e sofridos)

24- Formas de conviver / laços de solidariedade / relaçôes comunitárias

25- Relação com a natureza 
26- Religiosidades pretas

27- Relação com as mais velhas e os mais velhos / senhoridade (respeito aos mais experientes)

28- Vocabulário afro / formas de falar

29- Relação com o chão (vivências e simbologias)

30- Outras práticas corporais (brincadeiras tradicionais, jogos e outras)

Montamos várias técnicas e diversos dispositivos que nos permitissem suscitar ou fortalecer o pertencimento afro, o qual conceituamos como o autorreconhecimento e a valorização da sua conexão com o legado africano, presente em maior ou menor grau no nosso corpo-memória, queiramos ou não, pela inegável influência africana na brasilidade, ao mesmo título que as culturas indígenas e europeias.

Veremos a seguir um exemplo extraído de pesquisa intervenção defendida na Academia, com abordagem pretagógica e utilizando-se dos marcadores das africanidades como um dos motes.

\section{Exemplo de trabalho voltado ao fortalecimento do pertencimento afro realizado com os marcadores das africanidades e as estaçóes de aprendizagem}

$\mathrm{Na}$ escola do quilombo da Serra do Juá (CaucaiaCeará), Cláudia Oliveira da Silva (2015) estudou, sob a minha orientação enquanto professora universitária, o tema "pertencimento afroquilombola". Fez isso a partir dos marcadores das africanidades identificados: primeiro na história de vida da pesquisadora, mediante a narrativa de sua relação com as africanidades desde a infância, pois ela é filha desse território quilombola; em seguida, foram identificados marcadores apontados pela comunidade em atividades anteriores em uma investigaçáo sobre o ser negro quilombola, retratado a partir de um personagem montado coletivamente:
Práticas Pedagógicas para a Lei № 10.639/2003: A Criação de Nova

Abordagem de Formação

na Perspectiva das

Africanidades 
Sandra Haydée Petit

Educ. Foco, Juiz de Fora, v.21, n.3, p. 657-684 set. / dez. 2016670 o Pai José. O grupo-alvo foi intergeracional e composto de professoras, alunos, pai de alunos e comunidade em geral - em torno de 15 pessoas, em média, em vários ciclos de oficinas.

Em outro momento foram realizadas oficinas sociopoéticas (SILVA, 2014), abordagem que envolve o corpo todo na produçáo de dados. Naquela abordagem, o objeto cabaça foi usado para o grupo interagir em círculo e suscitar suas associaçóes com as africanidades. Em uma oficina ulterior, os copesquisadores conseguiram trazer suas lembranças e associaçóes imaginárias a partir de uma narrativa produzida com os resultados da vivência da cabaça, fazendo-os percorrer de olhos vendados um caminho onde encontravam lugares marcados pelas africanidades. Graça a essa técnica sociopoética intitulada de lugares geomíticos, foram surgindo espaços da ou na natureza como poço, cachoeira e mato. Nesses lugares significativos ao grupo, eles associaram lendas e vivências de forte interação com a natureza - mas também formas de convivência comunitária. Da Silva (2015), então, agrupou os marcadores e os retrabalhou distribuindo-os, ao que denominamos estações de aprendizagem, no caso cantinhos com materiais relativos a diferentes subtemas do tema gerador pertencimento afroquilombola.

Foram organizadas cinco estaçóes:

A primeira delas teve como assuntos o congraçamento e a culinária do subtema geral Relações Comunitárias. Ela possuía, dentre seus materiais instrutivos, objetos (piláo de madeira, panela de barro, livros, mapas, imagens de pessoas negras) e alimentos (melancia, gengibre, açafrão, banana, inhame, ervas frescas, rapadura, castanha de caju). $\mathrm{Na}$ estação, foram apresentadas receitas de moqueca de banana e inhame, dois elementos típicos daquela comunidade. Também foi sugerida a leitura de trechos do livro Sabores da África, da autora ganense Dorinda Hafner (2000). Nele, a autora trata dos significados do ato de comer, contextualizando culturalmente o valor desse ato como forma de congraçamento. O livro Ewé Orisá (BARROS, 2007) foi aproveitado para trazer as 
propriedades terapêuticas e usos litúrgicos desses vegetais nos terreiros de candomblé de filiação Kêtu-nagô (etnia iorubana - Nigéria).

Toda estação exige que os participantes se apropriem dos materiais colocados, para depois realizarem uma tarefa, a qual chamamos de produto didático - um artefato ou obra artística que o grupo elabora permitindo promover uma transversalidade de conhecimentos (literatura oral com suas diversas linguagens, história, geografia, ciências, tecnologias), sempre dentro da cosmovisão africana. Nessa estação, foram realizadas as receitas de moqueca de banana e de cozimento do inhame, para depois ser pilado de modo tradicional. Sabemos que, além dos valores trabalhados de congraçamento e espiritualidade, essa culinária também permite relacionar com aspectos de ciências como nutrição, física e química.

$\mathrm{Na}$ segunda estação, a pesquisadora tratou das relaçóes de solidariedade, que contou com o apoio pedagógico de ideogramas adinkras relativos a esse valor, bem como a partir do livro infantojuvenil Os Sete Novelos, de Angela Shelf, que traz uma história ganense de sete irmãos que ficaram órfãos de seu pai e tinham uma grande herança, mas que devido à desunião não conseguiam evoluir, até que perceberam que poderiam juntar seus dons de tecelás e produzir belos Kenté (panos tradicionais da nobreza, repletos de simbologias.). A estação tinha também novelos e imagens de adinkras, retalhos e croché. Para o produto didático, esse subgrupo foi estimulado a levantar as relaçóes comunitárias de solidariedade e lembraram do passado quando desciam a pé a serra com enfermos deitados na rede para levar até o doutor. Hoje essa prática caiu por fazerem uso de motocicletas.

A terceira estação abordou as temáticas da intergeracionalidade e mestria. O principal material foi o livro Olelê, de Fábio Simóes e Heloisa Pires, que retrata, dentre outros aspectos, a relação entre jovens e velhos.

Sobre o assunto mestria, a pesquisadora apresentou um documentário sobre a história de Mestre Vitalino em
Práticas Pedagógicas para a Lei № 10.639/2003: A Criação de Nova Abordagem de Formação na Perspectiva das Africanidades
Educ. Foco, Juiz de Fora, 671 v. 21, n.3, p. $657-684$ 
Pernambuco, que fazia objetos de barro conhecidos no Brasil todo. O documentário de meia hora mostra como ele aprendeu e se iniciou nesse ofício e como esse ensinamento vem sendo repassado. O produto didático trouxe os paralelos encontrados na comunidade, com a produção em argila de figuras e objetos que retratavam mestras(es) daquele quilombo, como a costureira Dona Socorro, que faz colchas de retalhos, e Seu Zé da Lourdes, o sanfoneiro. Assim, contaram suas histórias e formas de aprender e repassar seus ensinamentos, com aspectos de iniciação.

Explica da Silva (2015, p. 88):

$\mathrm{Na}$ temática da Ancestralidade, o documentário do mestre Vitalino, inspirou os(as) nossos(as) mestres(as) para que representassem suas artes através de objetos feitos com argila e com eles refloresceu a memória. Maria do Socorro falou que sua mãe trabalhava com barro e que esses objetos eram bem conhecidos pelas pessoas da comunidade, tendo em vista que há quarenta anos eram os vasilhames mais comuns nas casas, assim como as cabaças e cuias.

Maria do Socorro representou sua arte. Fez de argila uma máquina de costura e um alguidar de barro, porque lembrou da arte de sua mãe que era louceira e fazia objetos para vender e utilizar em casa. $\mathrm{O}$ aspecto da oralidade fica bem visível nessas açôes[,] pois ela aprendeu a fazer observando mãe trabalhar e[,] além disso, conhece muito bem como viveu seus antepassados.

Aqui, procuramos valorizar os mestres e mestras da comunidade. O mestre da sanfona[,] José Antonio da Silva do Nascimento[,] é quilombola, nascido em 13 de junho de 1963, na Serra do ajudar sua mãe a sustentar a família, depois que seu pai foi assassinado. Continuou por algum 
tempo militando no movimento social da comunidade de Porteiras, assim como seu pai fazia, lutando pela Reforma Agrária. Participava também em outros município com o grupo que fazia parte e[,] em uma dessas viagens do Movimento, conheceu um padre e externou seu desejo de ser sanfoneiro. Ganhou de presente de um sacerdote uma pequena sanfona, que lhe motivou a praticar, então aprendeu a tocar sozinho e hoje está sendo reconhecido pelo seu trabalho de músico.

José Antonio transparece a vontade de repassar seu aprendizado para os jovens da comunidade, mas sente a desmotivação deles(as). A sanfona[,] para ele[,] é sua riqueza e a representação de sua história de resistência. É conhecido pelo apelido de Zé da Lourdes, pois adquiriu esse nome por ser o filho que esteve sempre ao lado de sua mãe (Lourdes) para ajudar no sustento e na educação de seus irmãos.

$\mathrm{Na}$ quarta estação, com a temática geral ancestralidade, da Silva (2015) colocou de novo adinkras, como vemos abaixo - dessa vez, relativos a essa dimensão da cosmovisão africana.

\begin{tabular}{|c|c|c|c|}
\hline $\begin{array}{c}\text { Owo Foro } \\
\text { Adobe }\end{array}$ & Sesa Wo Suban \\
$\begin{array}{c}\text { A cobra sobe a } \\
\text { palmeira ráfia. }\end{array}$ & $\begin{array}{c}\text { Mude ou } \\
\text { transforme seu } \\
\text { caráter. }\end{array}$ & $\begin{array}{c}\text { Nunca é tarde } \\
\text { para voltar e } \\
\text { apanhar o que } \\
\text { ficou para trás. }\end{array}$ & $\begin{array}{c}\text { As garrafas da } \\
\text { águia. }\end{array}$ \\
\hline
\end{tabular}

Figura 1 - Representação dos adinkras.

Fonte: Da Silva (2015).
Práticas Pedagógicas para a Lei № 10.639/2003: A Criação de Nova Abordagem de Formação na Perspectiva das Africanidades 
Os livros apresentados foram: Orukomi, da autora Esmeralda Ribeiro, sobre o ritual de atribuição do nome na etnia Yorubá na Nigéria; Epé Layié - Terra Viva, escrito pela Mãe de Santo Stella de Oxóssi, relacionando educação ambiental e orixás, e $\mathbf{O}$ Comedor de Nuvens, de Heloísa Pires Lima, que mostra também a relaçáo com a natureza e os perigos das atitudes depredadoras e egoístas. O produto didático trouxe a reminiscência por meio da pintura dos antigos mutiróes, pois também foi exibido um documentário sobre a comunidade quilombola Morro Seco/Iguape em São Paulo, que volta a realizar mutirôes agrícolas após redescobrir sua importância no fortalecimento do senso de ancestralidade e pertencimento.

Por fim, na quinta estação, o tema foi brincadeiras e vivências quilombolas. Além de um artigo de livro acadêmico sobre quilombo, a investigadora colocou o livro infantojuvenil Falando Banto, de Eneida Gaspar (2011), mostrando algumas palavras brasileiras de origem bantu, instigando a se relacionar com termos usados no quilombo da Serra do Juá.

Para a dimensão brincadeira, foram realizadas como produto didático bonecas de pano que trazem memórias de brincadeiras antigas. No entanto, o produto que teve maior destaque foi o que reuniu todos os achados em uma obra só: o pano de pente afroquilombola. Partindo da referência da guineense Semedo (2010), foi realizada uma analogia com esse objeto, o qual originariamente tem um valor místico e ancestral muito forte de pertencimento cultural: a produção de um pano de pente pintado, e náo produzido no tear (como seria o tradicional). Cada banda do pano de pente foi pintada por um subgrupo de copesquisadores, juntando crianças, adultos e idosos, alunos, professoras e moradores em geral nessa produção. O resultado foi lindo, permitindo que a comunidade quilombola se visse retratada com uma bela obra de pertencimento afroquilombola. 


\section{Alguns produtos didáticos de outras pesquisas intervençóes pretagógicas}

Um exemplo foi a pesquisa de Alves (2014), que trabalhou com o tema gerador resistência negra, na busca de investigar as potências afro de um grupo composto por professores e alunos do Projovem Urbano com alunos da pedagogia, alguns deles também professores do ensino básico. Inicialmente, montaram árvores de seus afrossaberes, lembrando vários marcadores das africanidades presentes em suas vidas. Em seguida, os quatro subgrupos compuseram os produtos didáticos: um deles retratou as histórias de pertencimento afro de um dos subgrupos, com a montagem de um jogo de mímicas que fazia referência à visão de meio ambiente no culto aos orixás; outro criou um jogo de tabuleiro, com saberes relacionados à história e geografia envolvendo tipos de tecelagem afro; o terceiro produziu uma loa de maracatu (canto de maracatu, manifestação cultural do Nordeste brasileiro) com as histórias da comunidade; o último realizou uma crônica de autorretratos para trabalhar letramento (língua portuguesa).

$\mathrm{Na}$ pesquisa de intervenção pretagógica de Maria Eliene Magalhães da Silva (2015), a qual teve como grupo-alvo professoras, rezadeiras e demais moradoras de quilombo, um dos múltiplos produtos de destaque foi a inspiração nas capulanas (pano e vestimenta usada pelas mulheres em Moçambique), que partiu do livro Um pano estampado de histórias, de Heloisa Pires Lima e Mario Lemos (2014) - um breve documentário sobre o significado iniciático da capulana e a contação de um mito sobre a relação com o mundo das ervas, favorecendo entender também a dimensão da oralidade africana.

Assim, as copesquisadoras pintaram suas histórias e seus afrossaberes de quilombo em panos os quais usaram depois na forma de capulana, amarrados na cintura. Esse produto permitiu fortalecer, em muito, o senso de pertencimento afro de seu grupo de copesquisadoras, no caso composto por
Práticas Pedagógicas para a Lei № 10.639/2003. A Criação de Nova Abordagem de Formação na Perspectiva das Africanidades 
professoras e demais moradoras, que possuem em comum praticarem o ofício da reza, em diversos estágios de iniciação. A capulana forneceu uma analogia importante e motivadora pela sua dimensão iniciática e relação com a oralidade africana, disparando as memórias dos afrossaberes das mulheres copesquisadoras rezadeiras.

Já na pesquisa de Rafael Ferreira da Silva (2015), sobre as africanidades no ritual das ladainhas de capoeira, realizada com um público de quilombolas envolvendo professoras, alunos e moradores da comunidade, o produto didático que se destacou também foi a síntese de várias atividades, gerando a invenção pelos copesquisadores de letras de ladainhas a partir da apropriação de conhecimentos acerca dos significados de mestria e da musicalidade das ladainhas na capoeira, com depoimentos de mestres(as) de capoeira, curtas documentários, músicas de CD, livros infantojuvenis - como o Olelêe, de Fábio Soares e Heloisa Pires Lima (2014), a partir dos marcadores das africanidades relativos à ancestralidade africana, às práticas e aos valores de iniciação, à espiritualidade (religiosidades pretas), à musicalidade e às práticas corporais.

\section{CONSIDERAÇÓES FINAIS}

Os fatores que distinguem a Pretagogia nas pesquisas intervençóes realizadas pelos membros engajados nesse referencial são principalmente:

- A busca de conexáo com sua própria história das africanidades: tudo parte necessariamente da própria história do proponente da pesquisa intervenção que depois incentiva os participantes a também descobrirem suas histórias familiares e comunitárias, incluindo-se em uma rede de pertencimento afro.

- A busca de referenciais afro em todas as etapas do estudo propiciado ao grupo-alvo com materiais de grande diversidade de gênero e apelo a diversas linguagens: depoimentos de pessoas entrevistadas 
previamente, textos acadêmicos, livros de literatura (com ênfase na literatura infantojuvenil selecionada com critérios de qualidade informativa, ética e estética), músicas e letras do enorme repertório afrobrasileiro, músicas de outros países (africanos ou da afrodiáspora), objetos simbólicos, artesanatos, curtas documentários e ficcionais, mapas, panos, dentre outros elementos identificadores dos temas geradores.

- O favorecimento da autoria, criatividade, ludicidade, inventividade e metaforização filosófica da vida, na hora da produçáo didática, sem nunca perder o elo com o tema gerador e as dimensóes propriamente informativas.

- A aproximação com as tradiçóes orais africanas ressignificadas pelas analogias feitas com a cultura local e o contexto da aprendizagem, como a tradução de sentidos feita sobre as capulanas e o pano de pente, reelaboradas para fins pedagógicos em ambiente brasileiro.

- A transversalização das áreas de conhecimento trabalhadas nas estaçóes de aprendizagem e no produto didático, muitas vezes síntese das apropriaçôes de vários subgrupos.

- A quebra da hierarquização e do distanciamento entre as categorias envolvidas na pesquisa, sendo que todos os copesquisadores participam da realização do produto didático, independentemente de categoria profissional, faixa etária ou outra distinção social.

$O$ resultado final dessas pesquisas intervenção tem sido muito positivo, pois fortalecem pela co-autoria, o pertencimento afro enquanto afirmação de nossa relaçáo cultural com a ancestralidade africana, favorecem a relação comunitária e quebra de barreiras entre os grupos sociais e, sobretudo, promovem, em maior ou menor grau, a superação de posturas preconceituosas herdadas da nossa recente história de
Práticas Pedagógicas para a Lei № 10.639/2003: A Criação de Nova Abordagem de Formação na Perspectiva das Africanidades
Educ. Foco, Juiz de Fora, 
resistência e dor, ainda tão viva entre nós. Sobretudo, gera uma apropriação pedagógica de grande importância, com produtos didáticos cheios de significância. Daí é que surgem novas práticas pedagógicas cada vez mais instigantes, perpassadas da poética herdada dos saberes de nossos antepassados.

\section{REFERÊNCIAS}

ALVES, M. K. F.; MACHADO, A. F.; PETIT, S. H. (org.). Memórias de Baobá II. Fortaleza: Imprece, 2015.

ALVES, M. K. F. Resistência negra no circulo de cultura sociopoético: pretagogia e produção didática para a implementação da Lei $n^{\circ}$ 10.639/03 no Projovem urbano. 159 f. Dissertação (Mestrado em Educação Brasileira). Universidade Federal do Ceará, Programa de Pós-Graduação em Educação Brasileira, Fortaleza, 2015. Disponível em: <http://www.repositoriobib.ufc. br/000027/000027a8.pdf>. Acesso em: 10 jun. 2016.

BÂ, A. H. A tradição viva. In: História geral da África. São Paulo: Ática, 1982.

Amkoullel, o Menino Fula. São Paulo: Pallas; Athenas: Casa das Áfricas, 2003.

CUNHA JÚNIOR, H. Afrodescendência e espaço urbano. Fortaleza: UFC, 2007.

DA SILVA, C. O. Construindo o pertencimento afroquilombola através das contribuiçóes da Pretagogia no quilombo de Serra do Juá-Caucaia. Dissertação (Mestrado em Educação Brasileira). Fortaleza: Universidade Federal do Ceará, 2015. http://www. repositorio.ufc.br/handle/riufc/20842

LEMOS M.; LIMA, H. P. Capulana: um pano estampado de histórias. Sáo Paulo: Scipione, 2014.

MEIJER, R. de A. S. Valorizaçáo da cosmovisáo africana na escola: narrativa de uma pesquisa-formação com professoras piauienses. Tese. Fortaleza: Universidade Federal do Ceará, 2012. Disponível em: <http://www.repositorio.ufc.br/bitstream/riufc/7620/1/2012TESE-RASMEIJER.pdf $>$. 
MUNANGA, K. O que é africanidade? In: Revista Biblioteca Entrelivros - Vozes da África, São Paulo, edição especial, 2007, n. 6, p. 8-13.

OLIVEIRA, E. D. Cosmovisão africana no Brasil - Elementos para uma filosofia afrodescendente. Fortaleza: LCR, 2003.

Filosofia da ancestralidade: corpo e mito na filosofia da educação brasileira. Curitiba: Gráfica Popular, 2007.

PETIT, S. H. Pretagogia: pertencimento, corpo-dança afroancestral e tradição oral africana na formação de professoras e professores. Contribuiçóes do legado africano para a implementação da Lei no 10.639/03. Fortaleza: UECE, 2015.

PETIT, S. H.; SILVA, G. C. (org.). Africanidades caucaienses: saberes, conceitos e sentimentos. Fortaleza: EUFC, 2013.

SEMEDO, M. O. da C. S. As Mandjuandadi: cantigas de mulheres na Guiné-Bissau - da tradiçấo oral a literatura. Tese (Doutorado em Letras). Programa de Pós-Graduação em Letras. Belo Horizonte: Universidade Católica de Minas Gerais, 2010.

SILVA, M. E. M. da. Marcadores das africanidades no ofício das rezadeiras de quilombos de Caucaia-CE: uma abordagem pretagógica. 206 f. Dissertação (Mestrado em Educação Brasileira). Programa de Pós-Graduação em Educação Brasileira. Fortaleza: Universidade Federal do Ceará, 2015. Disponível em: <http:// www.repositoriobib.ufc.br/000027/000027a6.pdf>. Acesso em: 10 maio 2016.

SILVA, G. C. Tese (Doutorado em Educação Brasileira). Pretagogia: construindo um referencial teórico-metodológico, de base africana, para a formação de professores/as. Fortaleza: Universidade Federal do Ceará, 2013. Disponível em: <http://www.repositorio.ufc.br/ri/ bitstream/riufc/7955/1/2013-TESE-GCSILVA.pdf>.

SILVA, R. F. Africanidades no ritual das ladainhas de capoeira angola: pretagogia e produçáo didática no Quilombo. $132 \mathrm{f}$. Dissertação (Mestrado em Educação). Centro de Humanidades, Programa de Pós-Graduação em Educação. Fortaleza: Universidade Federal do Ceará, 2015. Disponível em: <http://www.repositoriobib. ufc.br/000027/000027ac.pdf>. Acesso em: 10 jun. 2016.
Práticas Pedagógicas para a Lei № 10.639/2003: A Criação de Nova Abordagem de Formação na Perspectiva das Africanidades 


\section{ANEXOS - PRODUTOS DIDÁTICOS}

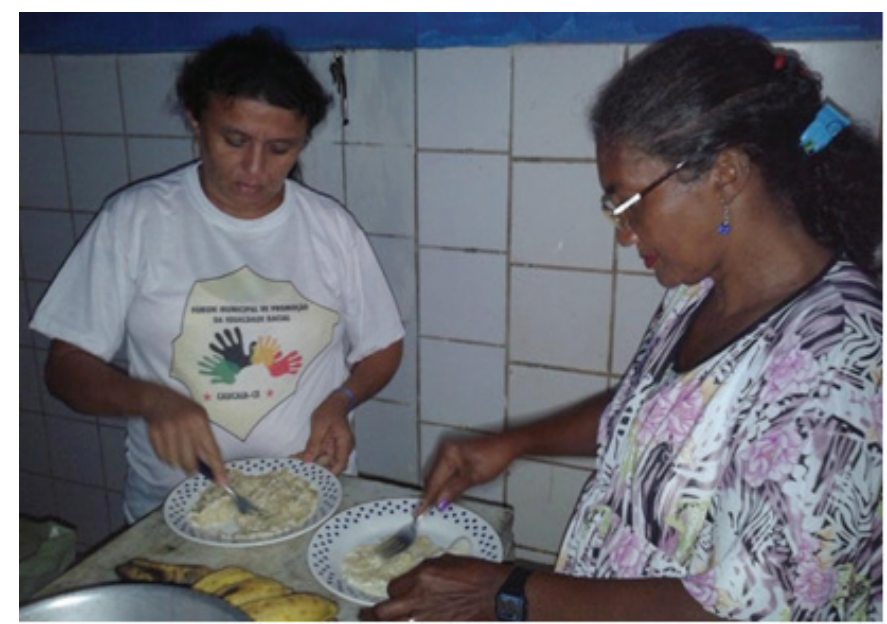

Figura 1 - Mulheres quilombolas Zuila e Dalva: preparando a moqueca de banana. Fonte: arquivo Cláudia de Oliveira da Silva.

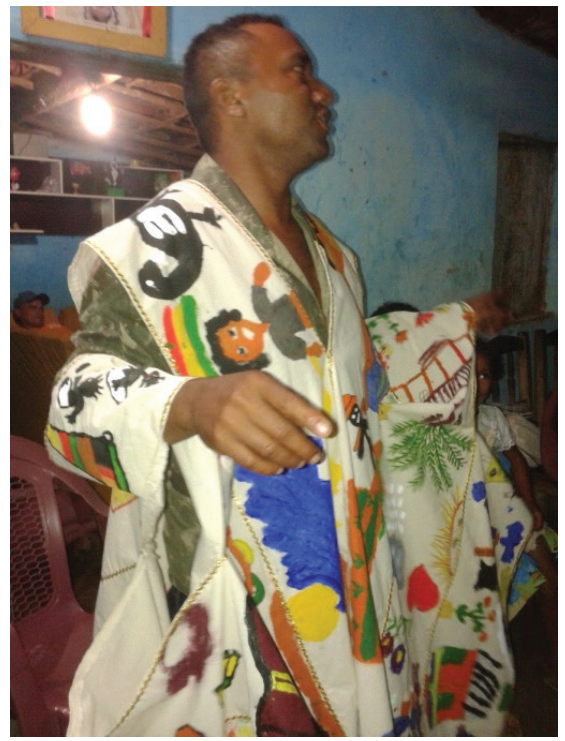

Figura 2 - Apresentação do Parangolé - Pano de Pente no Quilombo do Juá construído pelos quilombolas copesquisadores. Fonte: pesquisa Claudia Oliveira da Silva (2015) / acervo da autora. 


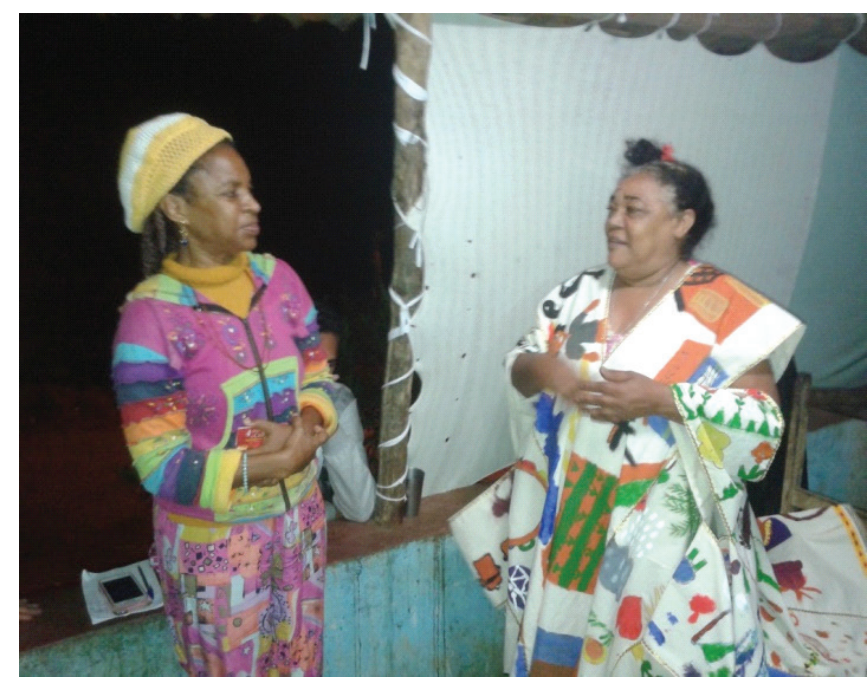

Figura 3 - Apresentação do Parangolé - Pano de Pente no Quilombo do Juá Dona Socorro fazendo seu personagem.

Fonte: pesquisa Claudia Oliveira da Silva (2015) / acervo da autora.

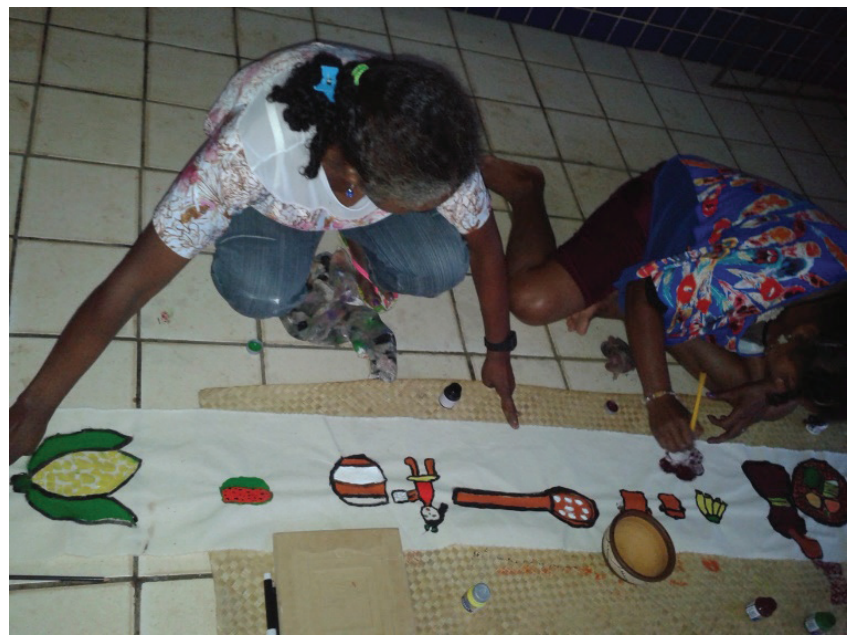

Figura 4 - Mulheres quilombolas: Dalva e Maria José: confeccionando a banda da culinária. Parangolé - Pano de Pente. Fonte: arquivo Cláudia de Oliveira da Silva. 


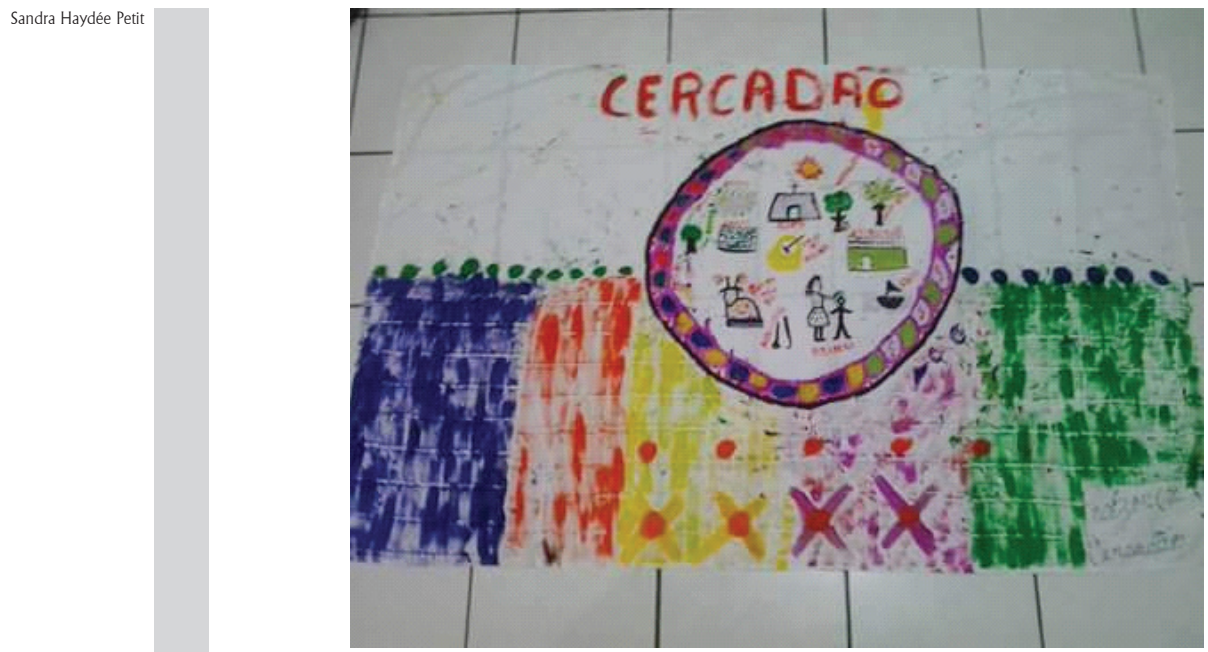

Figura 5 - Capulana dos Marcadores das Africanidades da Rezadeira Quilombola Dona Maria dos Prazeres.

Fonte: pesquisa Maria Eliene Magalhães da Silva (2015) / acervo da autora.

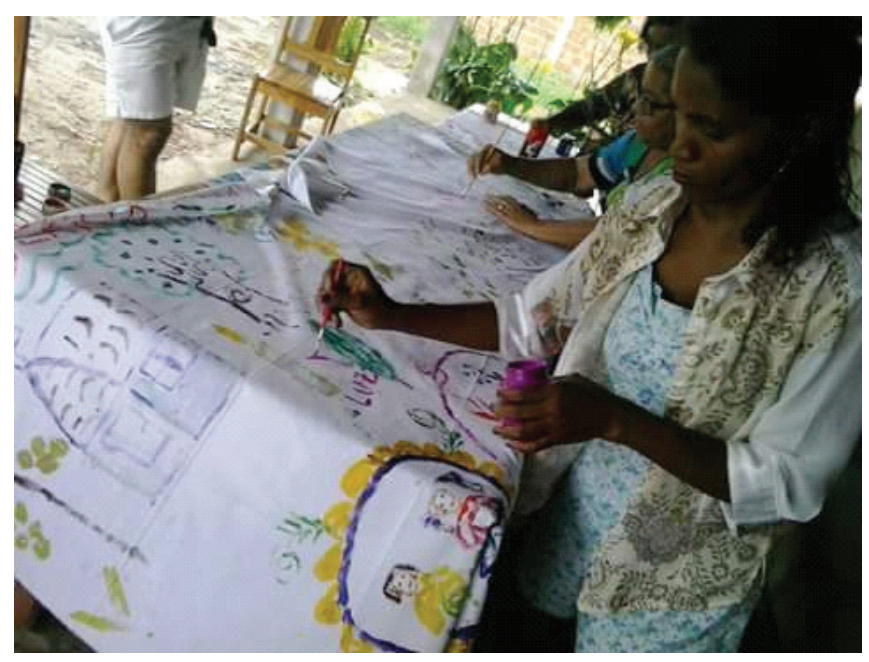

Figura 6 - Rezadeiras construindo o produto didático Capulanas dos Marcadores das Africanidades nas suas vidas.

Fonte: pesquisa de Maria Eliene Magalhães da Silva (2015) / acervo da autora.

Educ. Foco, Juiz de Fora, v.21, n.3, p. 657-684 set. / dez. 2016682 


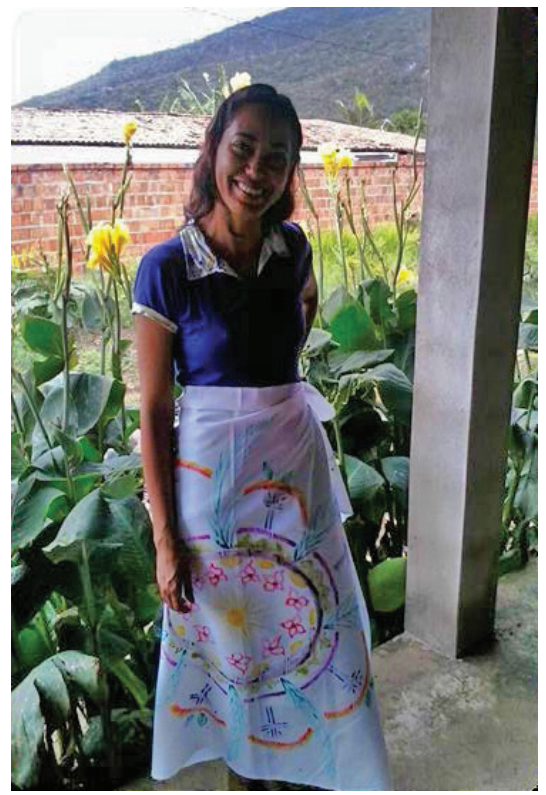

Práticas Pedagógicas para a Lei № 10.639/2003: A Criação de Nova

Abordagem de Formação

na Perspectiva das

Africanidades

Figura 7 - Rezadeira iniciante dona Maria Luiza de porteiras. Mulheres desfilando suas histórias de reza em pano capulana.

Fonte: pesquisa de Maria Eliene Magalhães da Silva (2015) / acervo da autora.

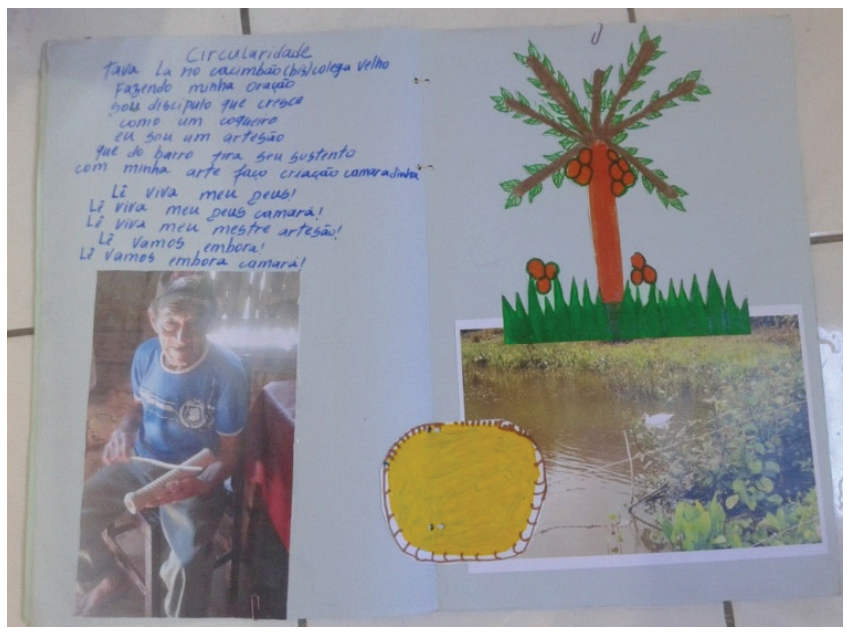

Figura 8 - Produto didático: Livro das Africanidades no ritual da Ladainha.

Fonte: Pesquisa de Rafael Ferreira da Silva (2015) / acervo do autor.
Educ. Foco, Juiz de Fora, 


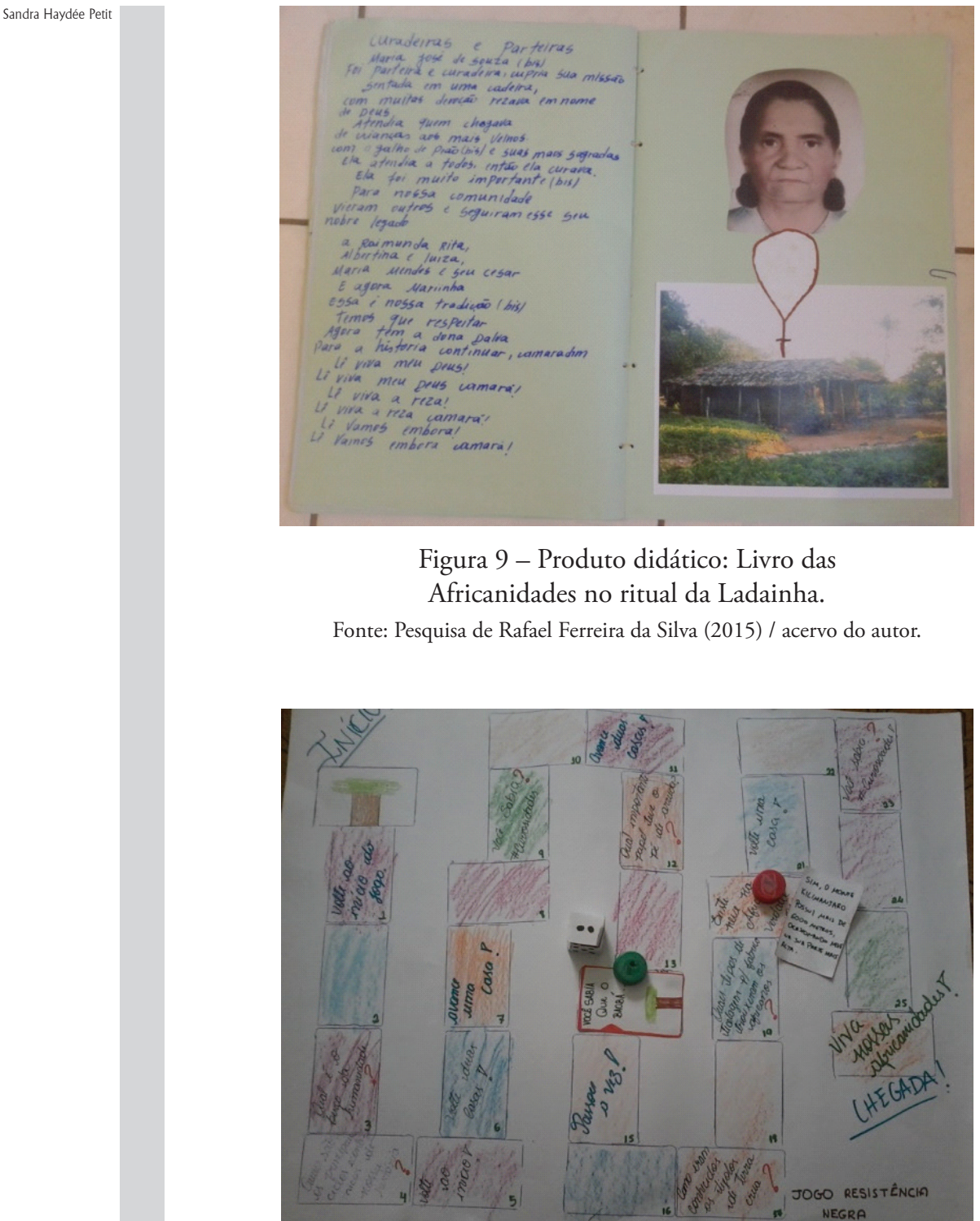

Figura 10 - Jogo de tabuleiro: 'Jogo da Resistência Negra'.

Fonte: pesquisa de Maria Kellynia Farias Alves (2015) / acervo da autora. 